\title{
Low-Frequency Propagation Paths in Arctic Areas
}

\author{
A. D. Watt, E. L. Maxwell, and E. H. Whelan
}

(December 19, 1958)

\begin{abstract}
The very low ground conductivities encountered in arctic areas, and the particular ionospheric conditions prevailing at high latitudes, can lead to rather unusual radiation and propagation conditions. In order to determine the magnitude of these effects, field intensities from transmitters located in the Labrador and Greenland areas were measured both on the surface of the earth and during several aircraft flights over this area. The many factors involved in lf propagation are considered and calculated field intensities compared with experimental values. Under conditions where the initial portion of the propagation path is across icecap or permafrost, the attenuation observed is very great, and when the propagation path extends out over sea water, the field intensity recovery taking place after the coastline is crossed is very marked. Estimates of skywave field intensity appear to agree with the observed results provided the radiated field pattern is suitably modified by the antenna cutback factor which accounts for the presence of a finitely conducting curved earth. These vertical patterns based on work by Wait, along with the field intensity flight data, indicate that the siting of low-frequency stations several miles or more inland in arctic regions may cause a great increase in total transmission path loss.
\end{abstract}

\section{Introduction}

During July and August of 1957, field intensities were measured from lf transmitters located in the Labrador and Greenland areas with primary emphasis being placed on transmissions from Thule, Greenland at $98.5 \mathrm{kc}$ and transmissions from Goose Bay, Labrador at $82.05 \mathrm{kc}$. The effective radiated power as a function of antenna current was obtained from each of the transmitters by observing the inverse field produced by the transmitter. All the field intensities presented are normalized to a transmitter radiated power of $28.7 \mathrm{kw}$. The actual field intensities on the surface were obtained by means of a 30 -in. loop and a field intensity meter which was calibrated by a signal injected in series with the loop. The aircraft measurements were performed using the antenna on the aircraft themselves, which were in effect top loaded monopoles. The effective height in each case was obtained by calibrations on the ground before takeoff by comparing the voltages from the antenna with the field intensity obtained by means of a loop positioned approximately $100 \mathrm{ft}$ from the aircraft.

\section{Observed Field Intensities}

The location of the transmitters and the surrounding terrain involved in the various flight paths are shown in figure 1 . The field intensity observed for the groundwave along the Thule to Goose Bay path over the permafrost and icecap is shown in figure 2. The x's represent observations taken very close to the path, while the circles represent observations made at various other locations in the Thule area. It is interesting to note that even at distances less than 10 miles, the intervening terrain has an appreciable effect on the observed field intensity.
In particular the two circles which lie on the inverse distance line at 5, 2, and 7.6 miles were for line-ofsight paths where there was a valley between the transmitter and the receiver. The next circle at 8.7 miles represents the field observed also on a lineof-sight path, but behind a glacier of about 1 mile extent in an open valley toward the transmitting site. It can be seen that this small icefield caused a 3-db decrease in field intensity. A similar abrupt decrease in field intensity was also observed when measurements were made on the edge and several miles out onto the main icecap. The two calculated groundwave curves were obtained from data by Wait $[1]^{1}$ and it can be seen that the surface field apparently follows the groundwave curve for the poor arctic land up to a point where the glacier is reached. Beyond this it begins to approach that for ice in a manner as would be anticipated from the mixed path theory as has been described by Millington [2] and Wait [3, 4].

Figure 3 shows the field intensities observed during flight 1 and it is interesting to observe the rather smooth slow variations which occurred over land till the coastline was reached at Hopedale. From here until Saglek was reached at some 300 miles from the transmitter the field intensity varied quite rapidly as the aircraft flew over the rather rough coastline and it is believed that these variations were caused by coastline effects [4]. The very deep null in the vicinity of the Button Islands appears to have been caused by interference between the first hop skywave and the groundwave. The rather large recovery in field intensity out to the vicinity of Cape Dyer is apparently caused by the decrease in over land transmission caused by the path swinging out over the Davis Strait. From Cape Dyer to Cape Atholl, the field decreased in a rather smooth manner and

1 Figures in brackets indicate the literature references at the end of this paper. 


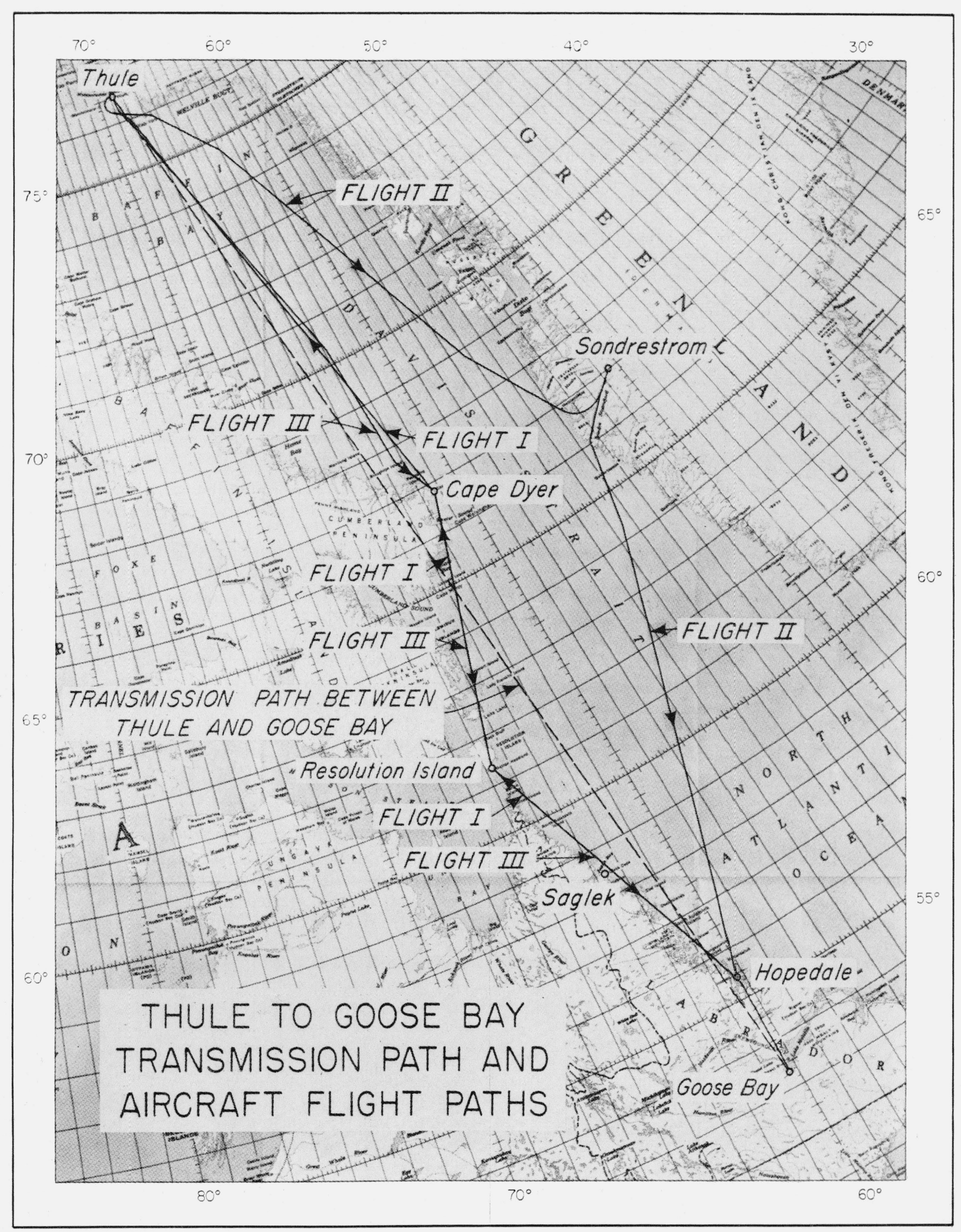

FIGURE 1. Baffin Island area with flight paths and transmitting and receiving locations. 


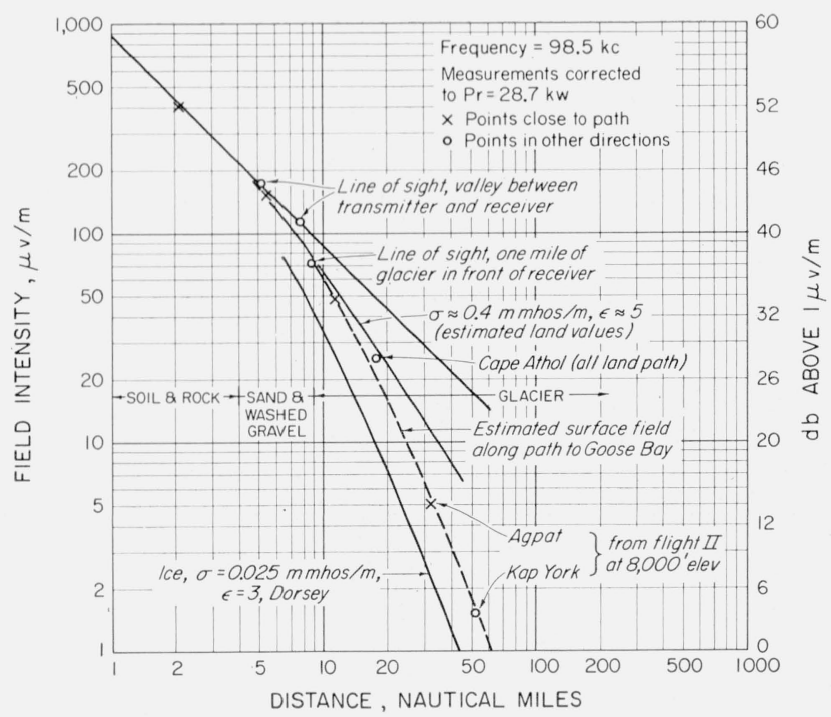

FIGURE 2. Groundwave field intensities in the Thule area.

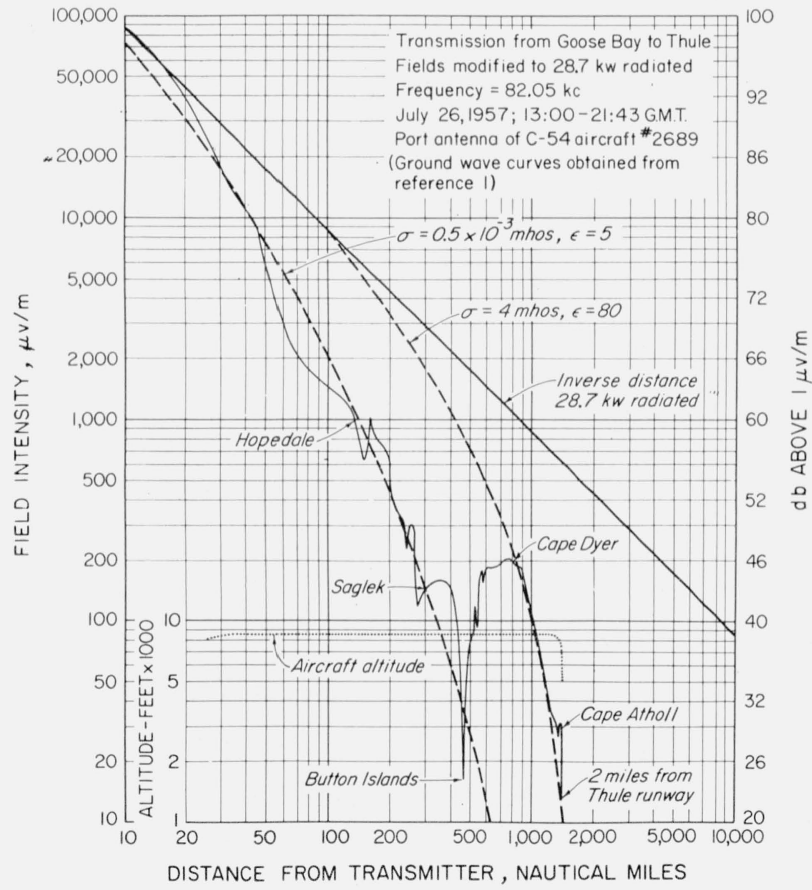

Figure 3. Field intensities fight 1.

no apparent effects were observed from flying over rather large patches of sea ice during this portion of the flight. Once Cape Atholl was reached, the field intensity began to vary at the coast and then decreased extremely rapidly until the last observation was made at 2 miles from Thule.

Figure 4 shows the field intensity from Thule as observed on flight 2. During the initial portion of this flight, the aircraft skirted along the coastline; however, once the aircraft departed from the coast, the field intensity rose considerably to a value

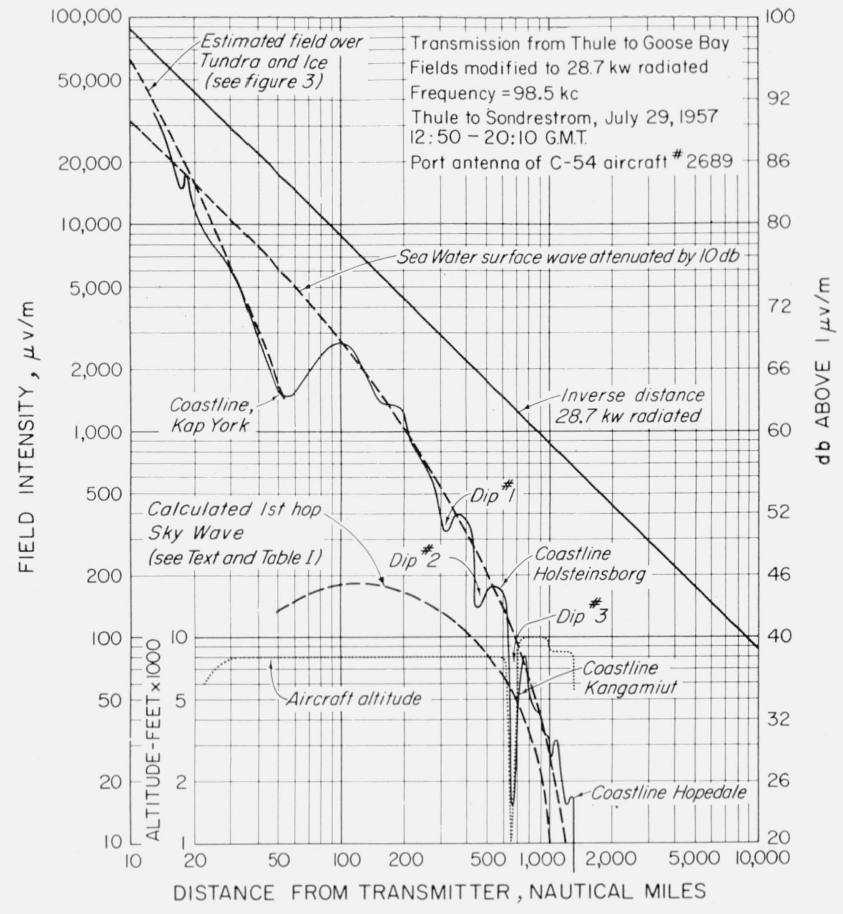

FiguRE 4. Field intensities fight 2.

approximately $6 \mathrm{db}$ higher than that observed at the coastline. Once this maximum recovery point had been reached, the field intensity is observed to drop in the manner anticipated for a surface wave over sea water from a transmitter with $10 \mathrm{db}$ less power than that actually radiated. The dips at 320 and 450 nautical miles appeared to have been caused by interference with the first hop skywave, and although dip 3 may be partially caused by interference between sky and groundwave, it is likely that a large portion of the reduction is due to the poorly conducting mountainous terrain in the vicinity. In fact, it can be seen that the field intensity dropped very rapidly once the coastline was reached at Holsteinsborg, and that it remained low until the coastline was again reached at Kangamiut. Once the coastline at Hopedale was reached, the field intensity decayed very rapidly apparently due to propagation over the rather poor earth in this vicinity. This decrease was so rapid that the field intensity dropped into the noise level at 100 miles from Goose Bay.

Field intensities from the Sondrestrom transmitter at $132 \mathrm{kc}$ were recorded during the second half of flight 2 , and are shown in figure 5 where it can be seen that the field is apparently influenced to quite an extent by the surrounding terrain.

The results obtained on flight 3 (fig. 6) are interesting in that, although the flight was made during the day, the ionosphere was apparently disturbed to the point where it appeared as highly reflecting as at night. This can be seen from the general increase in field intensities observed during this flight compared to flight 2 and from the diurnal variations in 
field intensity which were recorded at Goose Bay during, as well as preceding, this particular period. This particular flight also appears to contain a coastline dip with recovery effect; unfortunately, data was not taken that would record the exact depth of this dip. The rather high apparent ionospheric reflection coefficient present at this

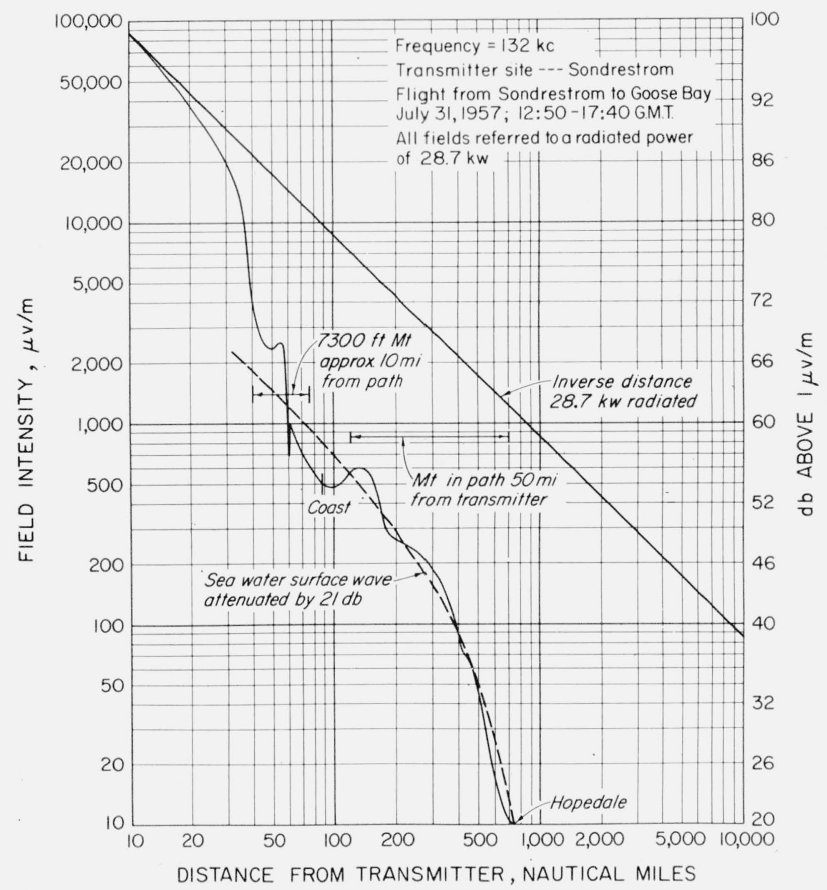

Figure 5. Field intensities flight $2 B$.

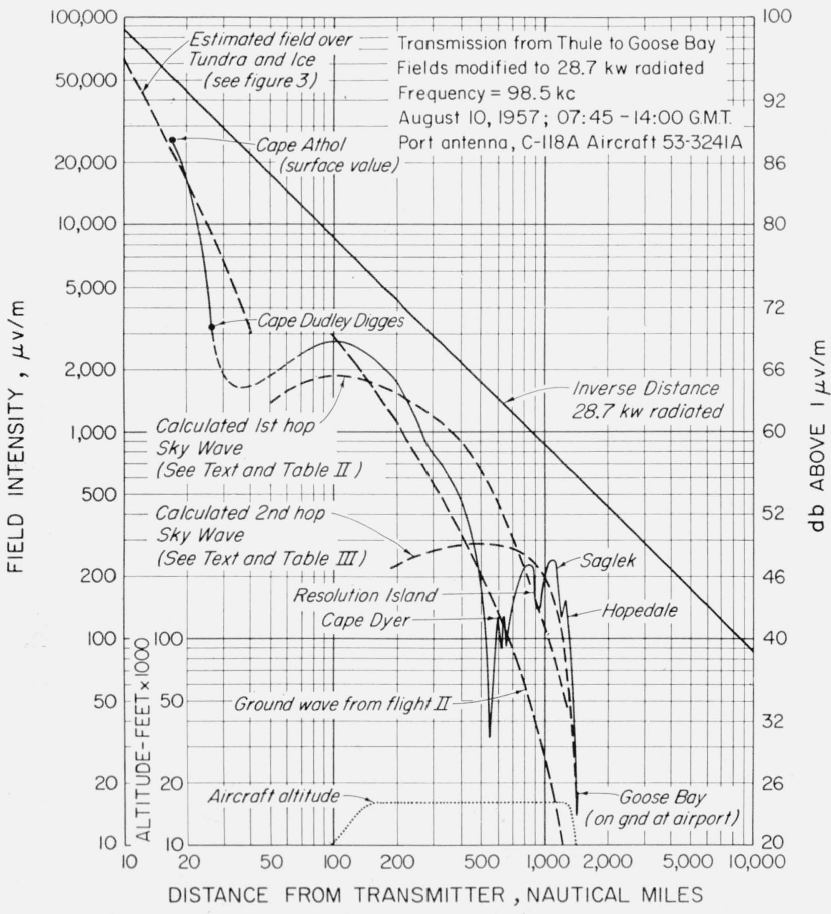

Figure 6. Field intensities flight 3. time raised the total field intensity in the region from 100 to 500 miles until a distance of 550 nautical miles was reached at which time there appears to be a canceling of energy received by the various modes. The lack of nulls up to this distance may be caused by a lower than normal layer height as well as by a possible fill-in from the $2 d$-hop skywave. After this null point was reached the field intensity recovered and remained rather high with some oscillations apparently due to coastline as well as interfering skywave effects until the coast was reached at Hopedale. At this point the field intensity again decreased very rapidly as in flight 2 , and is probably due to the receiving antenna cutback effect, i.e., out-of-phase ground-reflected energy.

Since it was anticipated that the coastline effect upon the groundwave may be somewhat different than that on an incoming skywave, a flight was performed over the icecap starting at a distance of approximately 30 miles from the coast and extending several miles out over the sea. This flight was performed at $6,000 \mathrm{ft}$ and the resulting field intensities from the Goose Bay transmitter, some 1,400 nautical miles distant, are recorded in figure 7 . It can be seen that there is a very great change in amplitude in the vicinity of the coastline apparently due to interference which is probably caused partially by the discontinuity in conductivity as described by Wait [4], and in part by the change in

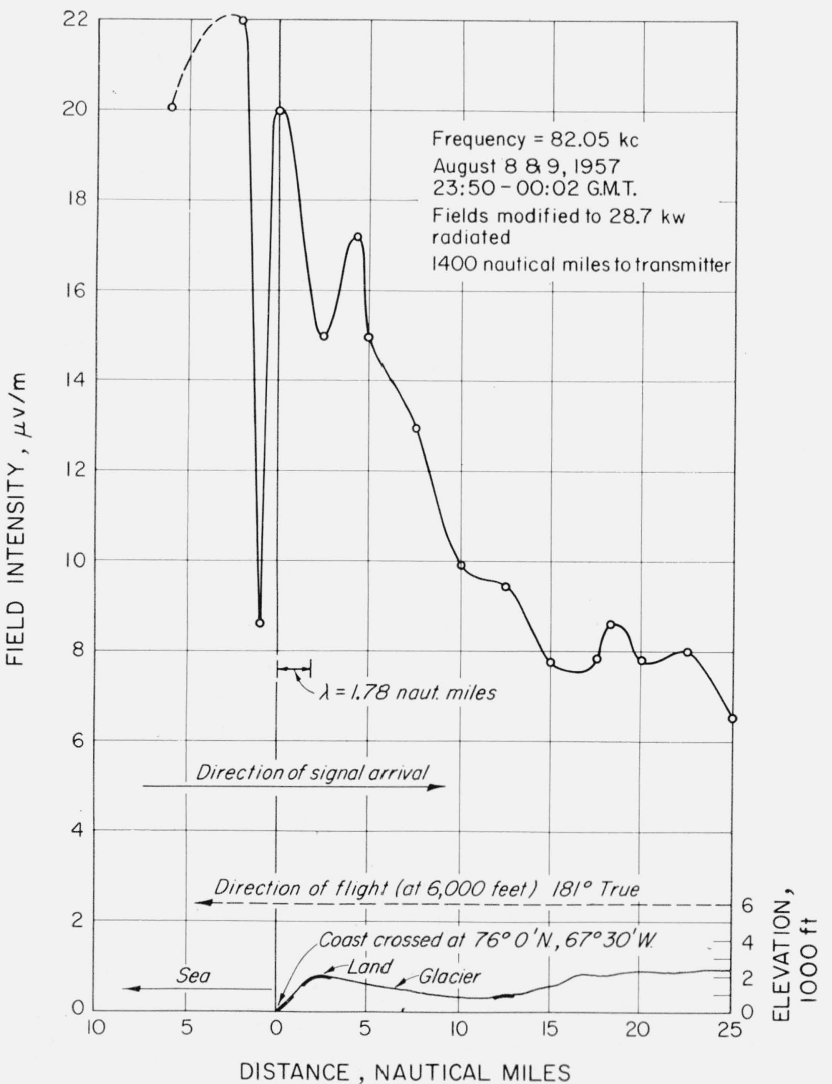

FiguRE 7. Coastline effect on low-frequency carrier amplitude fiom a distant transmitter. 
elevation of the coastal cliffs as also described by Wait and Murphy [5]. The manner in which the field intensity decreases with increase in distance inland gives some idea of the loss in transmission or reception efficiency at this frequency for radio stations located inland in arctic regions. It should be emphasized that these observations were made at a height of $6,000 \mathrm{ft}$ and that an even greater variation in field intensity is to be anticipated on the surface.

The manner in which the observed field intensities at Goose Bay vary with time can be seen in figure 8 , where the fields were effectively averaged over approximately a $10 \mathrm{~min}$ period. The first 4 days of observation on the field from Thule appeared to have very similar diurnal patterns with a rather high maximum occurring approximately $1 \mathrm{hr}$ after midnight. This rather short nighttime field is likely due to the fact that darkness exists for only a relatively short period of time at the 1-hop control point. During the day the field intensity decreased considerably and in general averaged around 2 $\mu \mathrm{v} / \mathrm{m}$.

A rather similar nightime maximum is observed on the 86-ke transmission from Keflavik although here the maximum peak occurred about $1 \frac{1}{2} \mathrm{hr}$ before midnight as might be anticipated from the path location. Field intensity recordings on $98.5 \mathrm{kc}$ were resumed on August 9 and the rather abrupt decrease just before midnight was observed as before; however, from this point on the pattern departed very markedly from that observed on previous days in that the field intensity remained rather steadily at a value almost $20 \mathrm{db}$ above the normal daytime values. It was fortunate that we were able to obtain a complete flight from Thule to Goose Bay during the time when this abnormally high field intensity existed.

To our knowledge, records of solar flares during this period do not indicate a very marked disturbance on the 10th and it is rather difficult to explain these high field intensities. The fact that the high field intensities were from the Thule transmission and not poise or interference is rather well substantiated by independent measurements of flight 3 and the system performance figures during this period.

Solar records do show that a large flare occurred on the 11th followed by an extremely large ionospheric and magnetic disturbance on the 13th; however, this could explain the high field during the day on the 11th but cannot explain our observation on the 10th. It may be that abnormal ionospheric conditions of this type are very easily caused in auroral regions and occur frequently.

\section{Analysis of Results}

In attempting to explain the observed field intensities, we shall employ the results of numerous theoretical and experimental investigators. The method employed will be to start at the transmitting site and determine radiation and launching efficiency and then follow the energy as it is propagated to the point of observation.

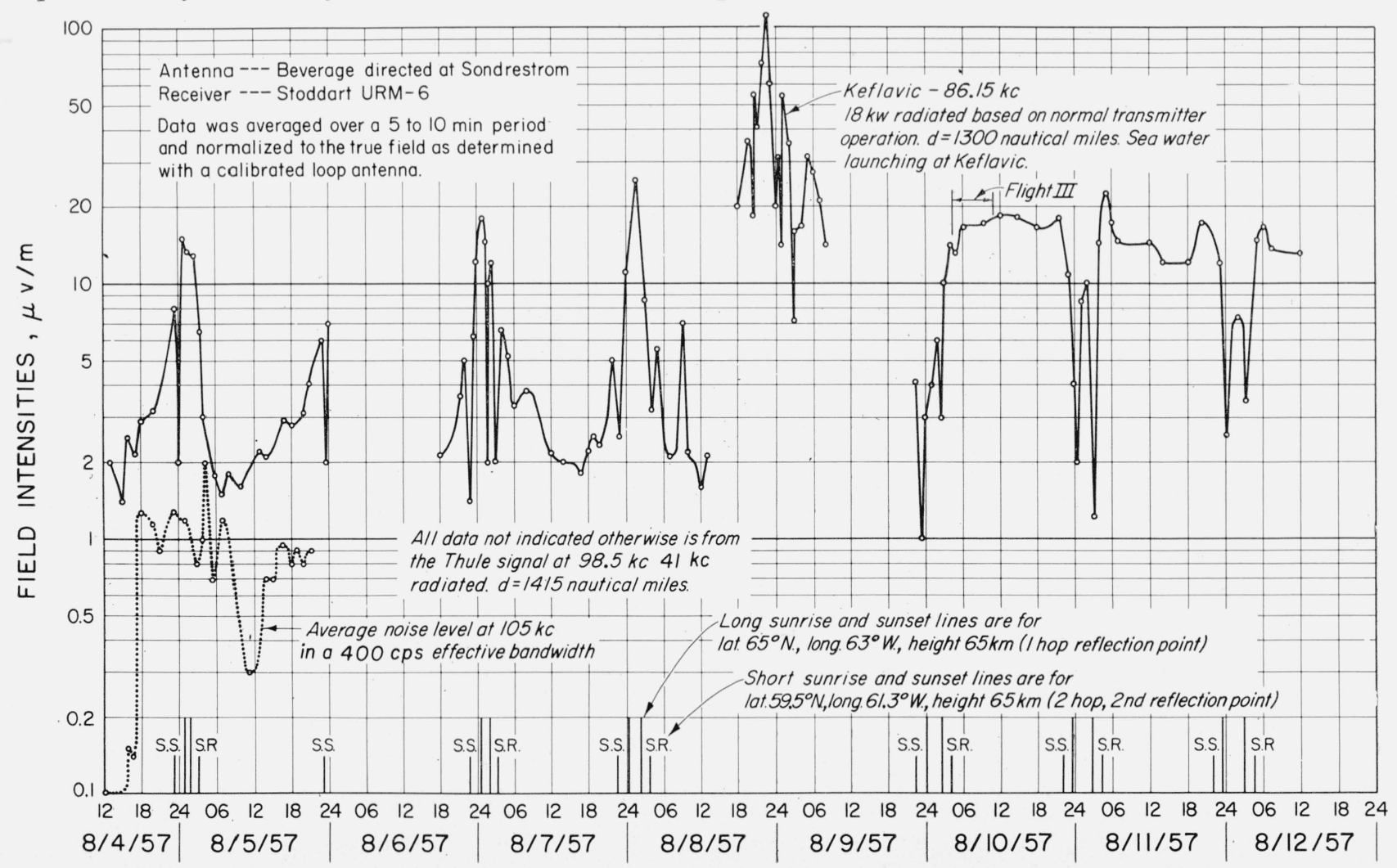

Figure 8. Diurnal field intensity variations as observed at Goose Bay, Labrador. 


\subsection{Radiating Systems}

The radiation efficiency for a given antenna is defined as the ratio of total power radiated to total power into the antenna. It is also well known that the radiation efficiency can be defined as follows:

$$
\operatorname{Rad} \text { eff }=R_{r} / R_{t}
$$

where $R_{\tau}$ is the radiation resistance and $R_{t}$ is the total resistance seen at the base of the antenna. $R_{t}$ can normally be measured while $R_{r}$ can be calculated for relatively simple configurations $[6,7]$. For a short vertical antenna we can write

$$
R_{r} \approx 40^{2} \pi\left(h_{a} / \lambda\right)^{2}
$$

where $h_{a}$ is the actual height of the vertical antenna and $\lambda$ is the wavelength. If the form of the antenna is complicated by top loading or supporting masts, it frequently becomes convenient to express the radiation resistance as

$$
R_{r} \approx 160 \pi^{2}\left(h_{e} / \lambda\right)^{2}
$$

where $h_{e}$ is now defined as the effective height of the antenna. Equations are available for calculating $h_{e}$ for numerous types of antennas; however, it may become necessary to obtain this value by means of measurements in the field. This well-known method actually involves field intensity measurements to obtain the effective radiation power using the relationship

$$
E=\frac{162.2 \sqrt{P_{r}}}{d}
$$

as described by Norton [8], which is good in the region $d$ greater than $\lambda$ and less than the point where the inverse distance relationship no longer holds. When the ground conductivity is unknown, it may be necessary to make observations at several distances to be sure that this distance is not being exceeded. If $E$ is in millivolts per meter, $d$ in nautical miles, the power radiated will be in kilowatts and it is relatively easy to then obtain the effective radiation resistance and the radiation efficiency of the antenna. It should be emphasized that eq (4) is based on the field from a short vertical antenna over a conducting surface, and that if the antenna height becomes greater than two tenths $\lambda$ it will be necessary to include a correction factor because of the vertical radiation pattern. In the low-frequency range it is usually possible to reduce the antenna tuning coil losses and insulator losses to the point where they are rather small compared to the ground resistance. In Arctic regions where the ground conductivity is low this factor must be carefully considered. Methods of calculating the effective ground system resistance are described by Wait [7].

Normally it is possible to obtain sufficiently good ground systems so that with tall radiators the effecrive radiation efficiency is relatively high in the order of 50 to 90 percent.

\subsection{Launching Efficiency}

It is well known that the propagation of groundwaves over poor conductivity material causes a very rapid decrease in field intensity; however, the effect of poor conductivity materials on the launched skywave are not as well known. Since an appreciable amount of the terrain in these northern latitudes consists of ice, we have included some of its electrical properties in figure 9 as has been obtained from Dorsey [9], where the $-5^{\circ} \mathrm{C}$ curves are expected to approximate conditions on the Greenland icecap, and the $-50^{\circ} \mathrm{C}$ curves for those conditions on the Antarctic continent.

The usual procedure for calculating the skywave field launched from a given transmitter is to first obtain the free space field intensity as given by eq (5).

$$
E_{f s}=\frac{81.1 \sqrt{P_{r}}}{d}
$$

where $d$ is again in nautical miles, $P_{\mathrm{r}}$ in $\mathrm{kw}, E$ in millivolts per meter, and then modify it by the reflection coefficient for a plain earth similar to those contained in [5, sec. 10]. Recent work by Wait has provided us with antenna terrain cutback factors which are calculated for launching over a spherical earth, and include fields for negative launching angles such as occur over rather long propagation paths. These terrain cutback factors are presented in figures 10, 11, and 12 for various conditions. In figure 10 the effect of various types of terrain in the vicinity of the transmitting antenna are shown for $100 \mathrm{kc}$, and it is apparent that the presence of ice with its very low conductivity causes a tremendous decrease in the launching effectiveness of a transmitting facility. For example, if a skywave is being launched at an angle of $0 \mathrm{deg}$, which would correspond to a distance of approximately 1,200 nautical miles, it can be seen that the effective transmitter

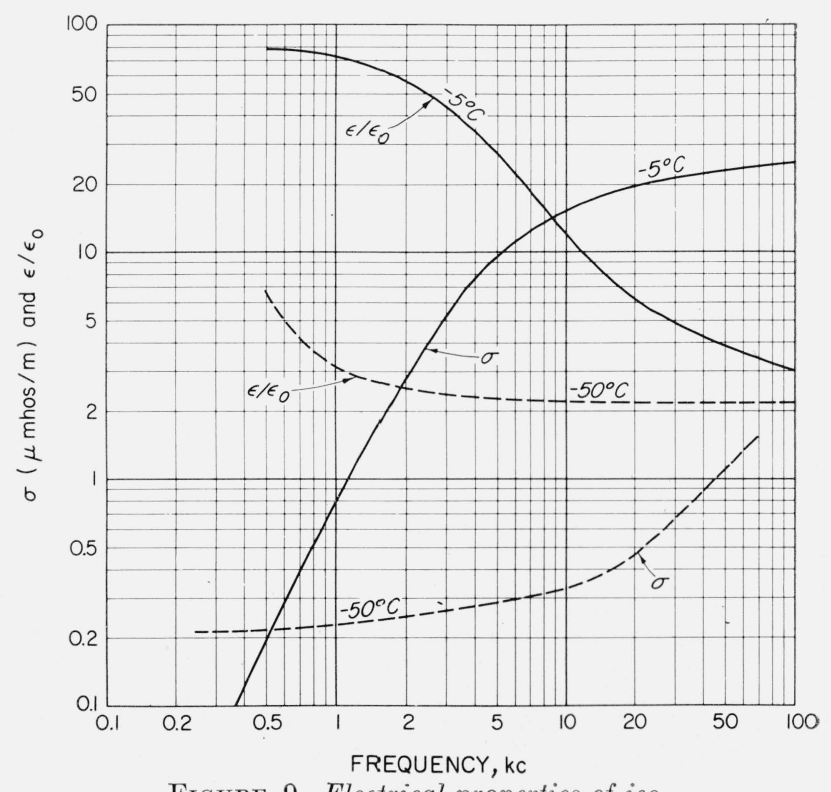

Figure 9. Electrical properties of ice. 


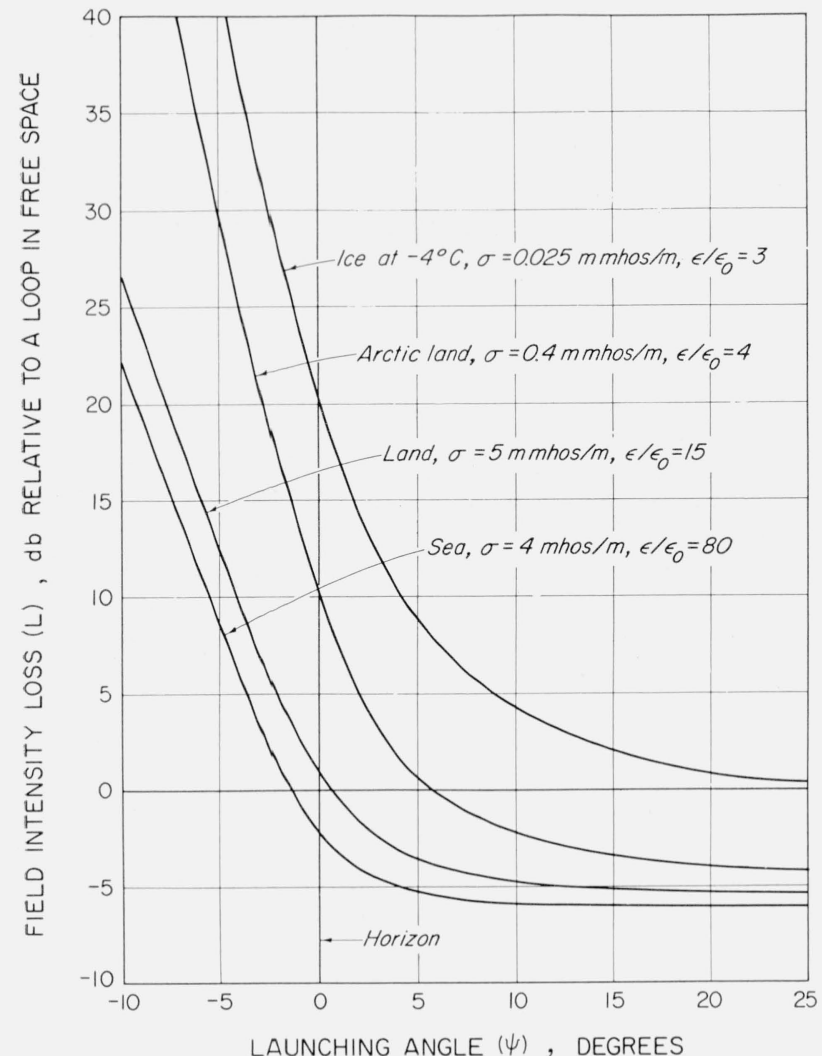

Figure 10. Terrain cutback factor for a loop antenna on the surface at $100 \mathrm{kc}$ (vertical E polarization) from Wait [9].

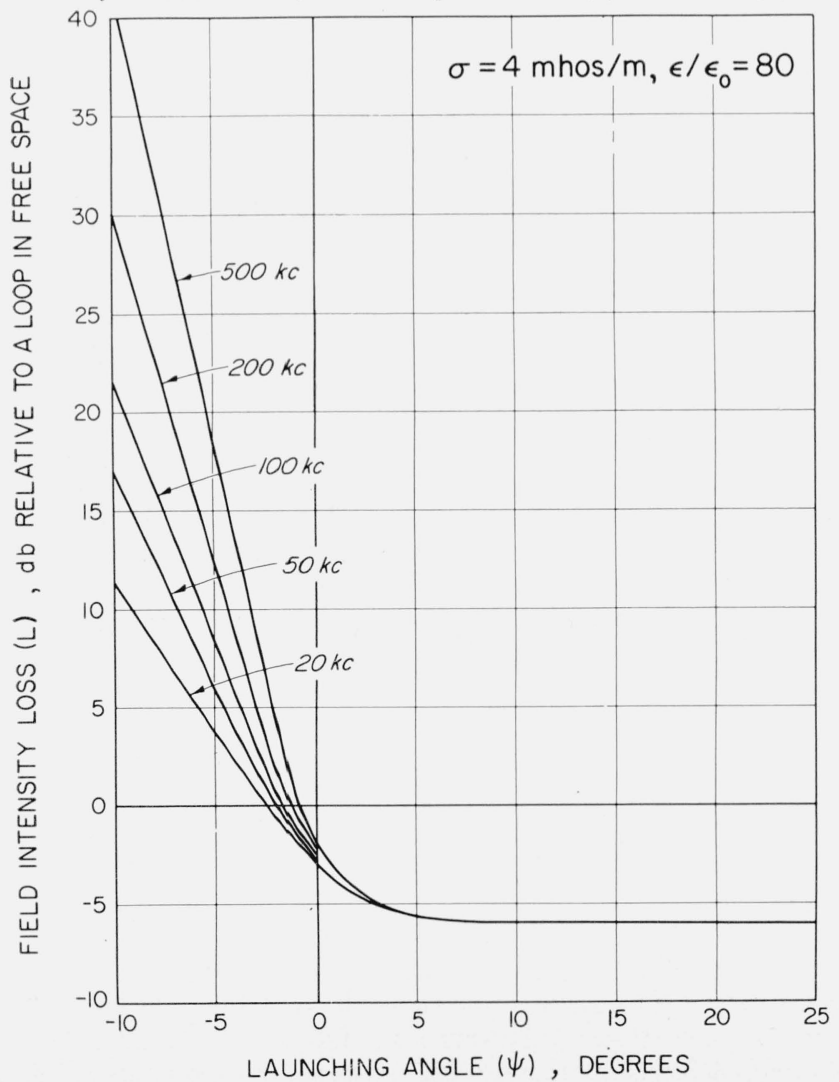

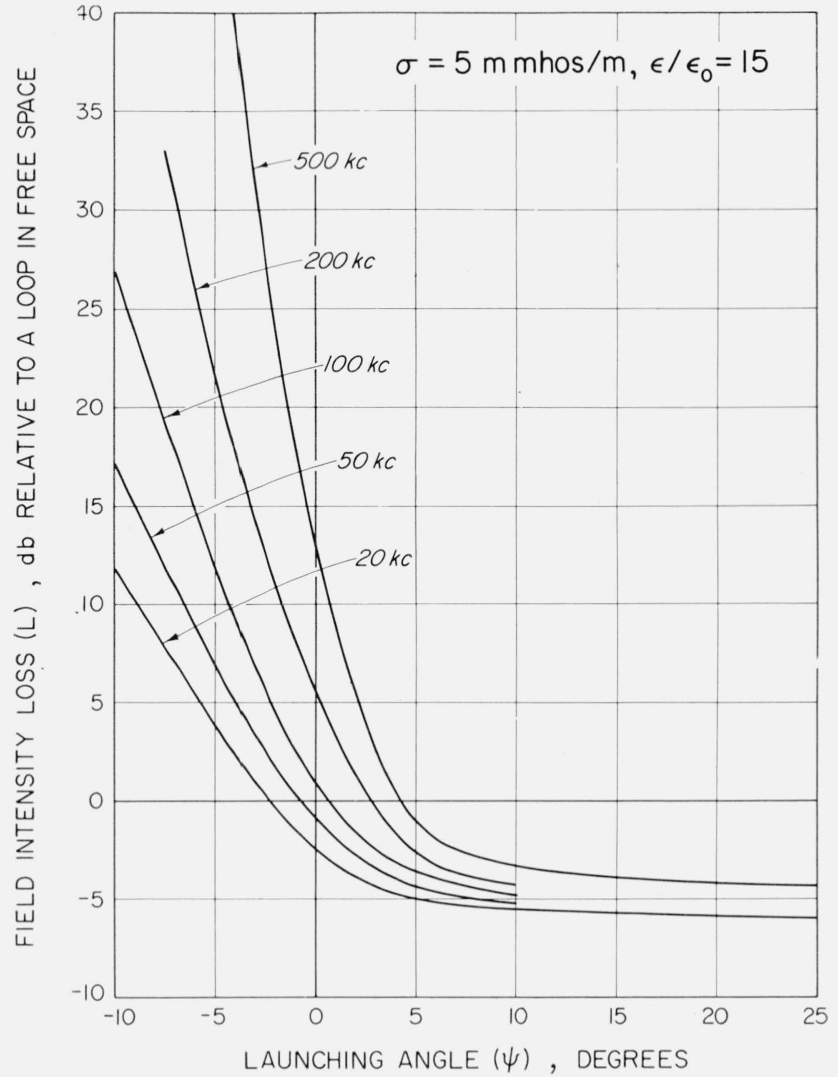

FIgURE 12. Terrain cutback factor for a loop antenna on the surface of average land (vertical E polarization) from Wait [9].

power is reduced by a factor of 100 compared to launching over good land or sea water.

This launching factor must also be considered at the receiving location and the same type of correction made for the appropriate terrain in the vicinity of the receiver. Frequently the receiver may be elevated above the surface such as was the case of our aircraft measurements. In these conditions a height gain function as described by Norton [8] must be employed. Values of this function in the If region for various types of terrain are shown in figure 13 .

One of the important questions that is still not adequately answered concerns the amount of poor conductivity or good conductivity terrain in the vicinity of an antenna that is required to make the terrain cutback factor curves applicable. This is a rather complex problem, but some idea of the factors involved can be obtained from the analysis employed by Norton [11], in which he shows the method of calculating Fresnel reflection zones in front of an elevated antenna. When the incoming wave is an ionospheric reflected one approaching at very low angles and with an antenna on the surface, the calculations become rather difficult especially when a spherical earth is considered. When nearly grazing angles are considered at a frequency of approximately $100 \mathrm{kc}$, it would appear that distances in the

FIgURE 11. Terrain cutback factor for a loop antenna on the surface of seawater (vertical E polarization) from Wait [9]. 


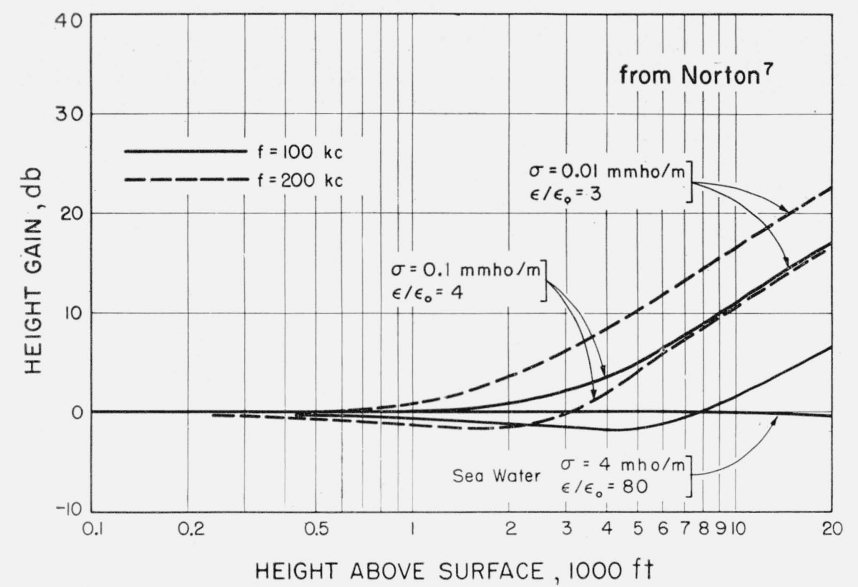

FIGURE 13. Height gain function. $G=\left|1+\frac{i 2 \pi h}{\lambda} \sqrt{\frac{i \epsilon_{0} \omega}{\sigma+i \epsilon \omega}}\right|$.

order of 30 miles may be important. An experimental investigation of this particular point can be seen with the aid of figure 7 where the amount of poor conductivity terrain in front of an elevated antenna was changed from 0 to 25 nautical miles. It is anticipated from other observations that the first hop skywave was essentially dominant at this time and that the incoming angle of arrival was approximately $-1 \mathrm{deg}$. Since the icecap in this region is not extremely thick, it is possible that the appropriate terrain cutback factor should lie somewhere between the arctic land curve and that for ice. If this was the case, we would anticipate a change of approximately $18 \mathrm{db}$ between the field observed over sea water and that inland as shown in figure 10. When we examine figure 7 we observe that the variation is closer to $11 \mathrm{db}$ and we now must observe that this field intensity curve was taken at an elevation of $6,000 \mathrm{ft}$ and that the height gain corrections must be applied. In figure 13 it is apparent that over sea water the height gain is essentially $0 \mathrm{db}$ while over the rather poor arctic icecap a correction in the order of $6 \mathrm{db}$ must be applied. When $6 \mathrm{db}$ is subtracted from the $18 \mathrm{db}$ difference in terrain cutback factors, we obtain a value of $12 \mathrm{db}$ which is in much closer agreement with that observed. It was also observed that the largest amount of reduction in field intensity occurred in the first 10 to 12 miles or about 7 wavelengths from the coast. This type of reduction indicates, as is expected, that the terrain in the immediate foreground that is several wavelengths in front of the antenna, is much more important in determining the losses in launching efficiency than the ground further removed from the antenna itself.

\subsection{Groundwave Propagation}

When the media separating the transmitting and receiving points is homogenous, the surface wave field can be obtained very readily from references [1 and 7]. Millington [2] and Wait [3] have considered the mixed path problem and it can be seen that even in the simple case of only two conductivities along the path that the calculation becomes complex. When the distance separating the transmitter and the discontinuity in conductivity is relatively small, it is seen from figure 2 that the transition from the form of variation with distance characteristic of the first medium to that of the second is rather rapid. On the other hand, when the distance from the transmitter is large, as for example in flight 2 , the recovery effect takes place over a much longer distance. This effect is very likely caused by the fact that close to the transmitter the field has a complex structure, while at longer distances the wave is somewhat characteristic of a plane wave. It should be mentioned that both the angle of propagation across the coastline and the height of observation will effect the rapidity of the recovery effect. After the transition period, from about 2 or 3 wavelengths to as much as 20 wavelengths, the groundwave is observed to behave in essentially the same manner as it would for a homogeneous medium with an increase or decrease in level depending upon the relative conductivities of the two media in question. As an example in figure 2 the field intensity appears to be following that anticipated for the over ice propagation at distances of 30 to 50 miles with an approximate $6-\mathrm{db}$ increase in amplitude apparently caused by the 8 miles of soil in the vicinity of the transmitter itself. On the other hand, in figure 4 the surface wave increases from that at the coastline to a point where it follows the sea water surface wave attenuation curve that is attenuated by $10 \mathrm{db}$ from that expected for a complete over water path. In other words, the 50 miles of tundra and ice in the vicinity of the transmitter have apparently caused a loss of $10 \mathrm{db}$ for the surface wave. It would also be anticipated that had the terrain in the immediate vicinity of the transmitting antenna been glacier, that instead of being $10 \mathrm{db}$ down, the field would have been approximately 16 db lower than for an all sea water path.

In figure 5 where transmission from Sondrestrom is observed at a frequency of $132 \mathrm{kc}$ the surface wave is observed to decrease quite rapidly going through some oscillations in the vicinity of 50 miles apparently due to a 7,000-ft mountain off to one side. Once the coastline was reached, the course of flight was changed so as to bring the path back into the shadow of this mountain and the recovery effect observed was appreciably less than anticipated apparently due to the shading effect of the mountain. Here the over sea water surface wave appears to approach a decay rate anticipated for a surface wave $21 \mathrm{db}$ below that for an all over sea water path. In this particular case the lossy media although not entirely glaciated, was very rough and produced an appreciable decrease in field.

A somewhat similar recovery effect was observed on flight 3; however, after the peak of the recovery was reached at approximately 100 miles from the transmitter, the rather high skywave reflection coefficient existing at this time caused an appreciable amount of skywave energy to be present so that it was impossible to determine from this flight the characteristics of the surface wave. 


\subsection{Skywave Field Calculations}

The general ray path geometry involved in skywave propagation is shown in the sketch at the top of figure 14 where the launching and ionospheric reflecting angles are shown. These angles and the cosine of the ionospheric reflection angle are given in figure 14 for an effective height of $70 \mathrm{~km}$ which corresponds to typical daytime conditions and for an effective height of $90 \mathrm{~km}$ in figure 15 which is an effective nighttime condition. The dotted lines on the 1-hop psi curve show the anticipated values when atmospheric refraction is included in the calculations. This particular effect, along with a much more detailed description of the phenomena involved in skywave propagation, is described by Norton [12]. The time delays between the skywave and groundwave based on ray path length differences is given in figure 16 so that some idea of the separation between cancellation and reinforcement points can be calculated. This figure is also employed to determine the total length of the skywave which is used in calculating the inverse distance field.

It now becomes apparent that the skywave is reduced by an antenna vertical pattern and a launching factor at the transmitting site. It is also decreased by absorption and polarization conversion at the ionosphere and increased by a convergence coefficient as described by Norton [12], where the combined effect is considered as the reflection coefficient ${ }_{\|} R_{\|}$which can become greater than one for oblique paths. On arriving at the receiving point the skywave is changed by the launching factor and vertical antenna pattern at the receiver and the

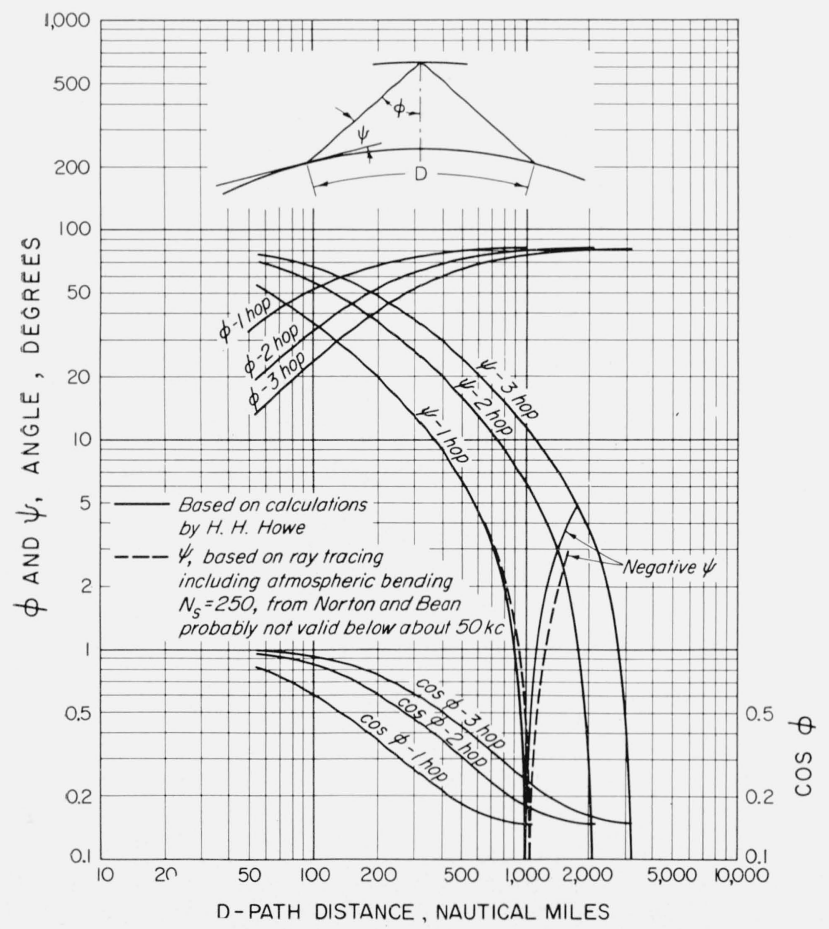

FIGURE 14. Ray path geometry and resulting angles for an effective layer height of $70 \mathrm{~km}$. height gain factor if an elevated observation point is considered. For multiple hops the additional ionosphere reflection and conversion coefficients and ground reflections must be included. This can be

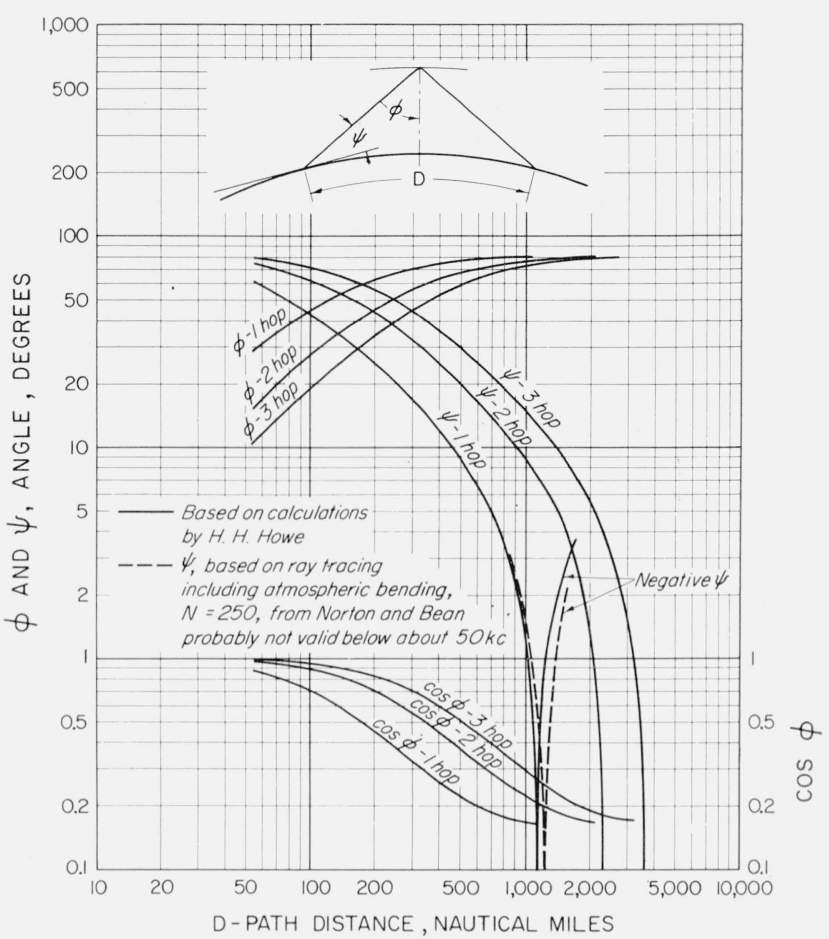

FIgURE 15. Ray path geometry and resulting angles for an effective layer height of $90 \mathrm{~km}$.

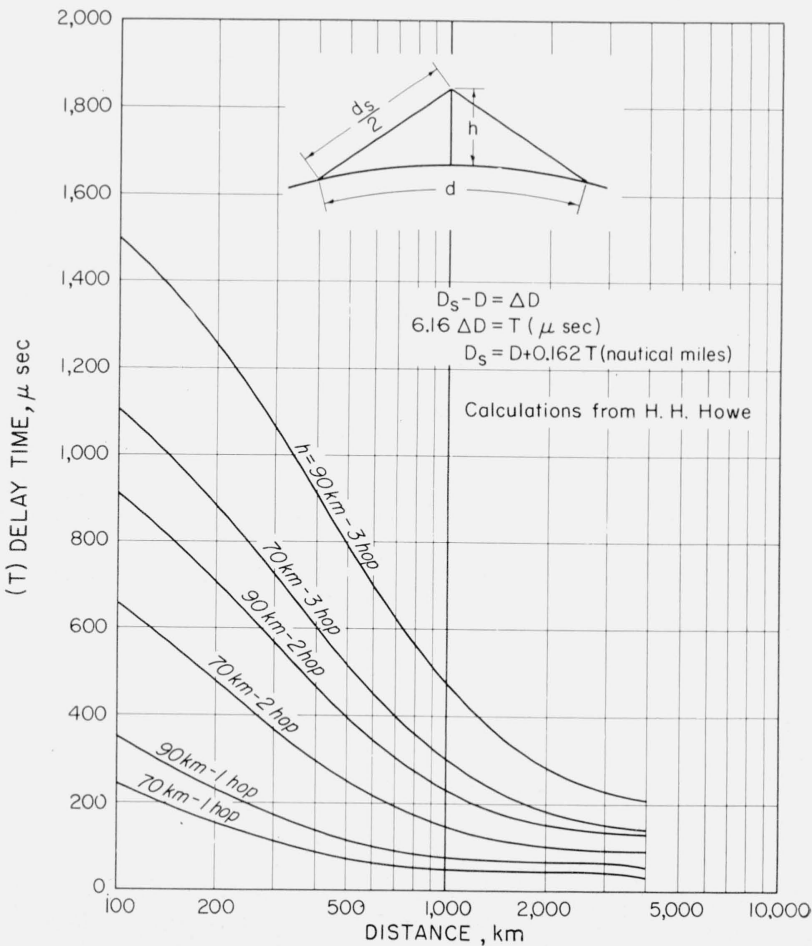

FIgURE 16. Transmission delay times between skywave and groundwave based on ray length only. 
summarized as shown in the following equation where instead of multiplying ratios, we shall add all the factors as expressed in decibels.

$E_{s \mathrm{~m}}=K+P_{r}-D_{p}+A_{t}-L_{t}-I+C_{\mathrm{m}}-(m-1)\left(I_{\mathrm{m}}+G\right)$

$$
-L_{r}+A_{r}+H
$$

$E_{s \mathrm{~m}}=m$ th hop skywave field intensity in decibels above $1 \mu \mathrm{v} / \mathrm{m}$,

$K=$ constant used in calculating free space field at unit distance,

$=98.2$ for nautical miles,

$=99.4$ for statute miles,

$=103.6$ for kilometers,

$P_{r}=$ power radiated in db above $1 \mathrm{kw}$ (see fig. 17 ),

$D_{p}=$ inverse distance attenuation in $\mathrm{db}$ relative to unit distance (see fig. 18),

$A_{t}=$ transmitting antenna free space gain in decibels at launching angle $\psi$ (see fig: 19),

$L_{t}=$ transmitting antenna launching loss in decibels relative to a loop in free space (see figs. 10, 11, 12),

$I=$ ionospheric reflection $\operatorname{loss}=-20 \log _{\|} R_{\|}+C_{m}$ (see figs. 21, 22, 23),

$m=$ number of hops,

$C_{m}=$ convergence at ionosphere in db (see fig. 20),

$I_{m}=$ ionospheric reflection loss for multiple hops which includes conversion as well as reflection coefficients,

$G=$ ground reflection loss in decibels (see fig. 24),

$L_{r}=$ receiving antenna launching loss in decibels relative to a loop in free space (see figs. 10, $11,12)$,

$A_{r}=$ receiving antenna free space gain at launching angle $\psi$ in decibels (see fig. 19), and

$H=$ receiving antenna height gain in decibels over surface value (see fig. 13).

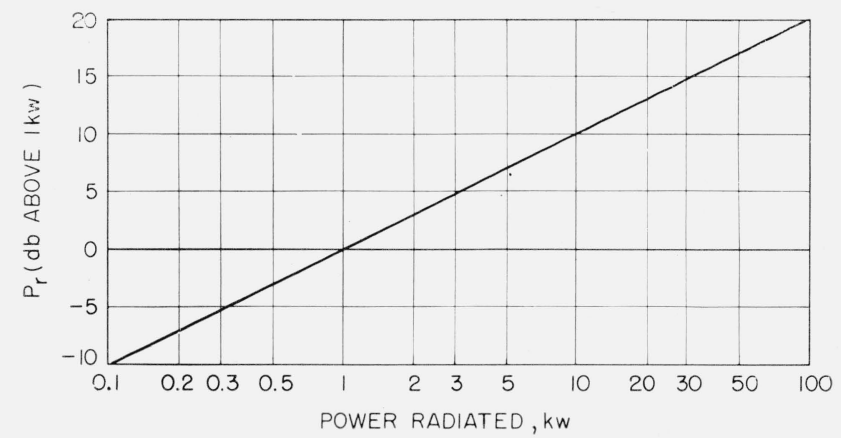

Figure 17. Power radiated in decibels above $1 \mathrm{kw}$.

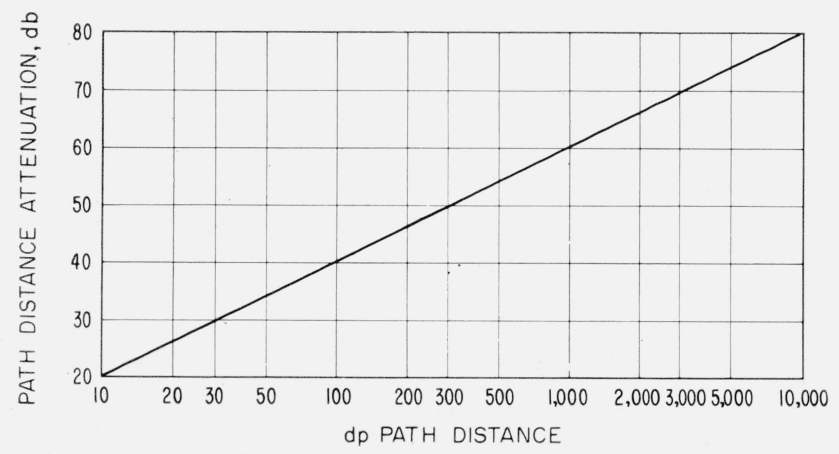

Figure 18. Inverse distance.
If the receiving antenna voltage is desired, it can readily be obtained by multiplying the field intensity in microvolts per meter by the effective height in meters.

Before attempting to apply this equation, we shall first consider the ionospheric reflection factor. It should be emphasized that the ionosphere is a very complex media, and that at present we only have an approximate knowledge of its structure. A recent survey of studies of the phase stability of ionospheric reflected radio waves from 16 to 500 kc has indicated

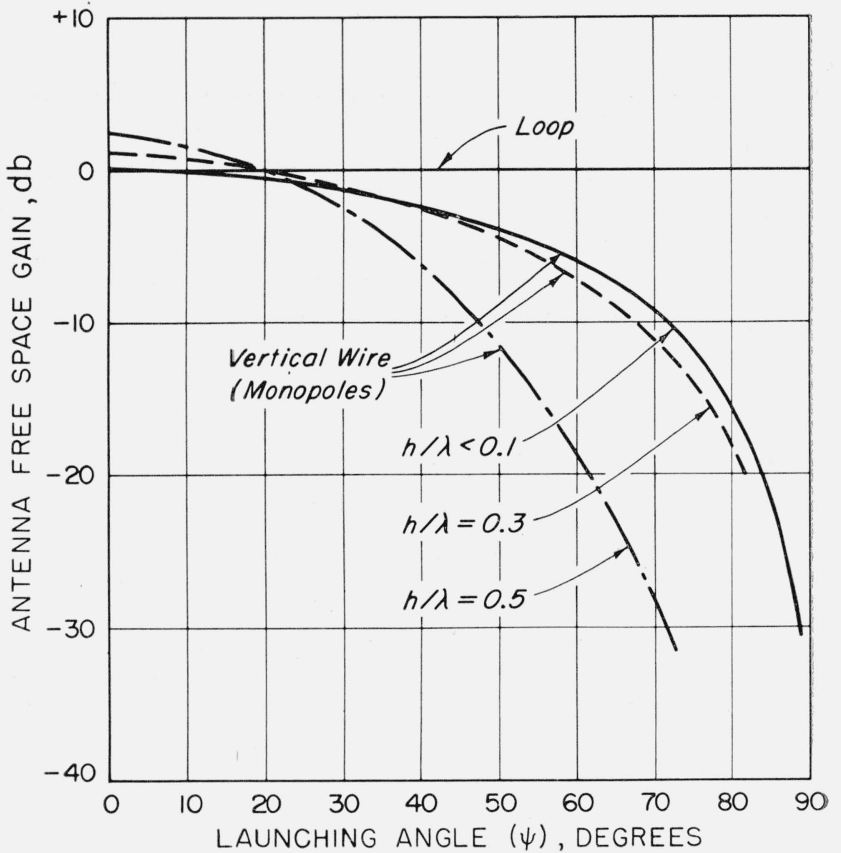

FIGURE 19. Antenna free space gain.

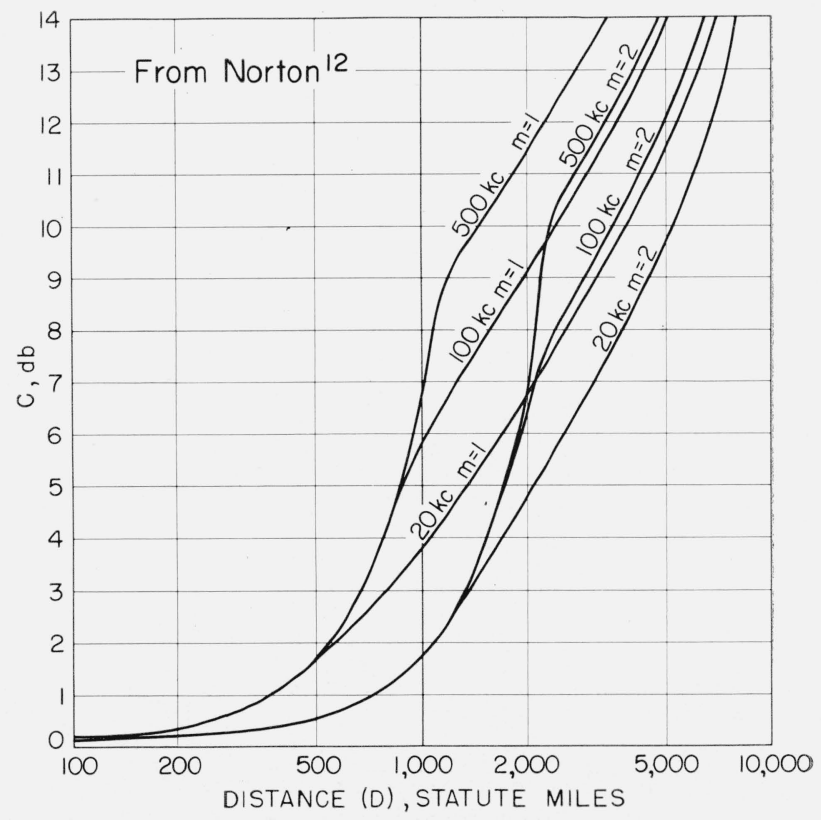

FIgURE 20. Ionospheric convergence factor.

$h-70 \mathrm{~km}$ (maximum convergence anticipated under smooth ionospheric condi$h-70 \mathrm{~km}$
tions). 
that during the day the ionosphere for most of the time appears very smooth at least to $100 \mathrm{kc}$ and probably beyond, and that at night the apparent roughness is only very slightly greater at vlf. At $100 \mathrm{kc}$ and higher, the ionosphere may be smooth enough to vield essentially specular reflection and as a result full convergence; however, in the region of $500 \mathrm{kc}$ the reflections may become fairly diffuse for an appreciable percentage (estimated 5 to 30 ) of the time.

On this basis, it can be seen that we should always employ the full value of $C_{m}$ at vlf and also at lf during the day, and that it may also be applicable up to $500 \mathrm{kc}$ for an appreciable amount of the time at night. Very excellent descriptions of many of the factors involved are given by Bracewell et al. [13] and Waynick [14]. Ionospheric reflection coefficients have been obtained by a rather large number of investigators [15 to 19] and their results along with some of our observations at Goose Bay and on flights 2 and 3 have been combined with appropriate corrections for antenna cutback factor where required and the results presented in figure 21. Here it is seen that the attenuation on reflection at $100 \mathrm{kc}$ increases with the cosine of the angle of incidence to a maximum value at vertical incidence. It also shows that the summer noon values are much higher than winter noon which in turn are also higher than the nighttime values. It also appears that the

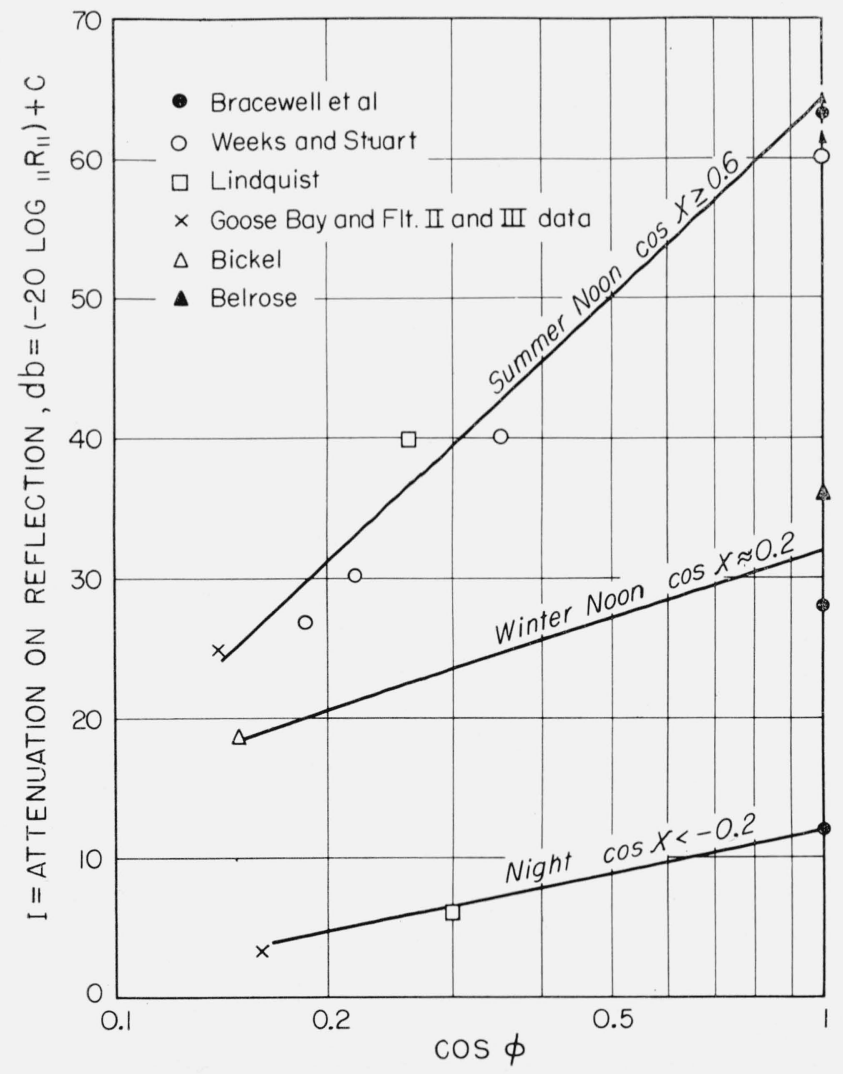

FIGURE 21. Inospheric reflection coefficient as a function of angle of incidence at $100 \mathrm{kc}$

Convergence factor removed. Estimated median values. Actual value at any time may differ appreciably from that shown. variation in attenuation upon reflection as a function of angle is much less at night than during summer days.

To prevent us from reaching the erroneous conclusion that this behavior is typical at all frequencies, we have included figure 22 which shows the attenuation on reflection as a function of the cosine of the angle of incidence for 16.6 and $40 \mathrm{kc}$. Here it can be seen that there is an appreciable Brewster angle effect with a maximum attenuation in the region of 70 to $75 \mathrm{deg}$. This type of behavior is anticipated at vlf and the lower If region below around $70 \mathrm{kc}$ where the ionosphere effective boundary is apparently rather smooth and sharp as described in a theoretical paper by Wait and Perry [21]. As the frequency is increased, the boundary becomes less sharp so that the Brewster angle effect is not anticipated at frequencies of $100 \mathrm{kc}$ and up. In order to determine the effect of different frequencies upon the attenuation on reflection, figure 23 has been prepared showing the loss for an angle whose cosine is equal to 0.15 . This corresponds to a distance of approximately 800 nautical miles. It can be seen that the loss on reflection increases rather rapidly with frequency during summer daytime conditions reaching a value in excess of $70 \mathrm{db}$ at a frequency of $700 \mathrm{kc}$. At noon in winter, the increase is less pronounced and during nighttime conditions the loss increases very little with frequency until $100 \mathrm{kc}$ is reached and beyond this point a maximum value of 10 to $20 \mathrm{db}$ in the region of $400 \mathrm{kc}$ is expected. One of the interesting apparent indications of the data making up this particular curve are that at very low frequencies, in the order of 15 to $20 \mathrm{kc}$, the reflection

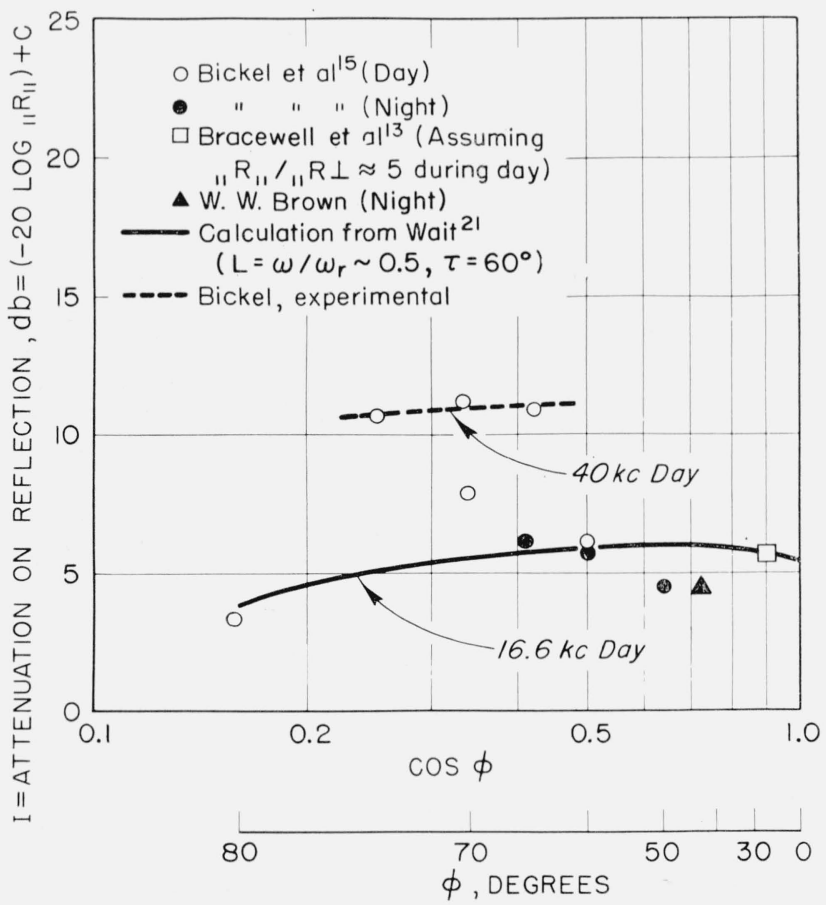

FIGURE 22. Ionospheric reflection coefficient as a function of angle of incidence at 16 and $40 \mathrm{kc}$.

Convergence factor removed. 


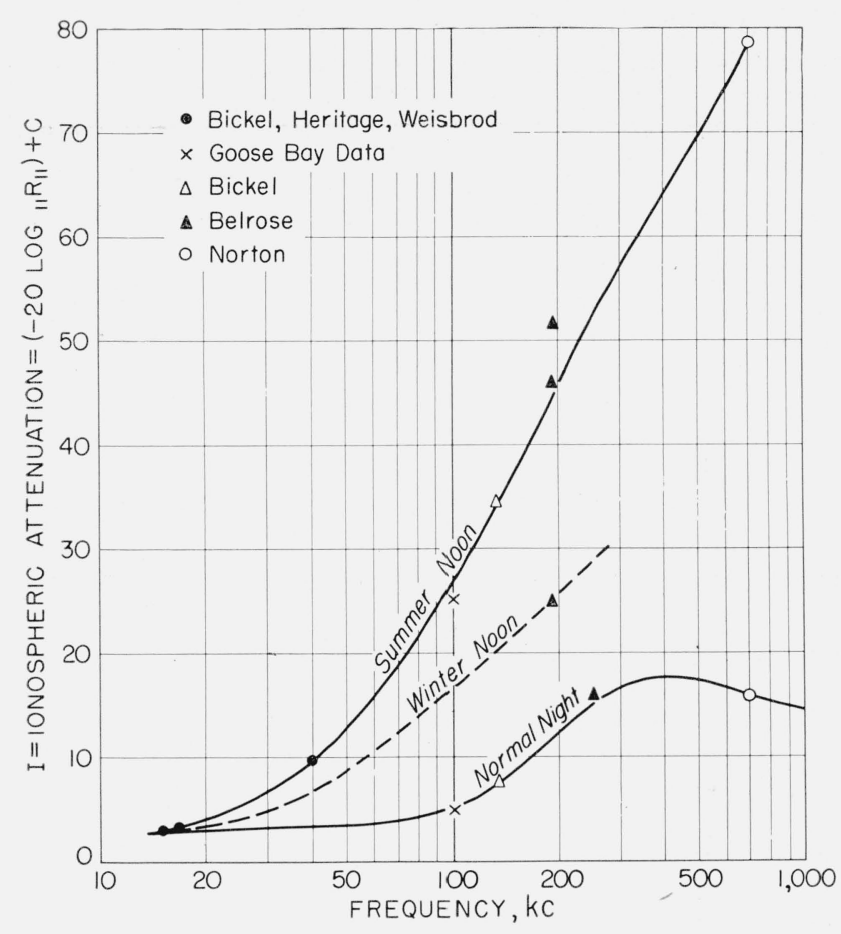

Figure 23. Approximate ionospheric reflection coefficient at grazing (cos $\phi-0.15),(\mathrm{d}-800$ nautical miles), for vlf and lf. Estimated median values.

coefficient at near grazing angles does not vary greatly either with season or time of day. This at first might seem to contradict the amount of observed increase in attenuation during the day over that observed at night. A closer examination of the problem by Wait [21], reveals that in general the increase in daytime attenuation can be explained by the lower height of the ionosphere with the corresponding changes in angles of launching.

The seasonal and diurnal variation of the ionospheric reflection coefficient are well known to be correlated with solar radiation as has been shown for example by Pierce [23] where he relates the path attenuation coefficient to the sun's zenith angle. The approximate zenith angles corresponding to the conditions described in figures 21 and 23 have been included to give a rough idea of this effect. It

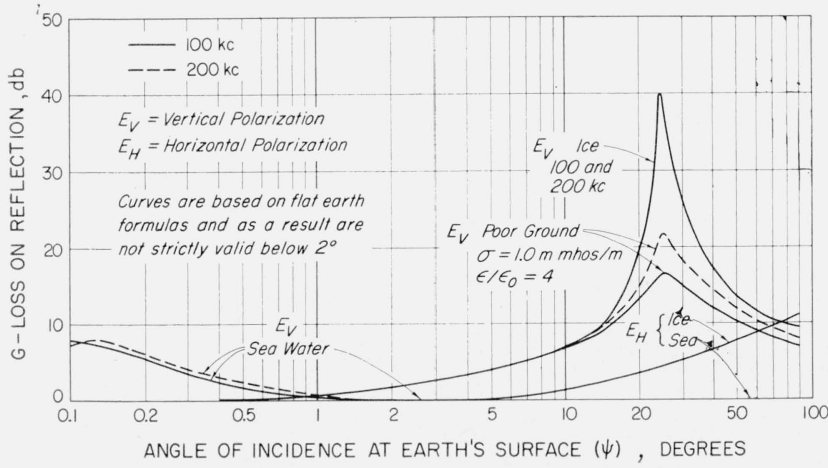

Figure 24. Ground-reflection attenuation. See Terman [5]. should be mentioned that sunspot activity will also affect the reflection coefficient and when more detailed curves of loss on reflection are prepared, they will undoubtedly include these effects. When more than one hop is considered, the ground reflection coefficient for each polarization must be considered as shown in figure 24 .

When determining the efficiency of a given carrier in the presence of noise and interference, it is necessary to know the characteristics of the fading as well as that of the interference present as described by Watt et al [24]. Unfortunately, statistical distributions of the instantaneous carrier amplitude were not obtained during these observations; however, from the recorder record with a 1 -cps band, the fade rate was observed to vary from fairly rapid excursions during the sunrise and sunset periods to slower variations during the day and short night periods. It was interesting to observe that the abnormally high field intensity periods recorded during the day of the 10th and 11th showed a very steady carrier level with essentially no fading at all. This would tend to indicate that the ionospheric reflecting layer present at this time was much steadier than normally observed.

Some of the fading characteristics as described by Bowhill [20] are shown in figure 25 where it is interesting to observe that the fade rate is generally very low at frequencies below $70 \mathrm{kc}$ and that it increases at higher frequencies. Bowhill also points out that in the intermediate region of 60 to $100 \mathrm{kc}$ that fading records show the presence of both a slow component of the magnitude of $0.01 \mathrm{cps}$ and a high component whose rate is in the order of $0.2 \mathrm{cps}$. These fade rate observations combined with spaced receiver measurements indicate layer drifts in the ionosphere and rather random blob sizes which during the nighttime at a height of approximately $90 \mathrm{~km}$ appear to have an average effective horizontal size of $6 \mathrm{~km}$. At a $100-\mathrm{km}$ height as ob-

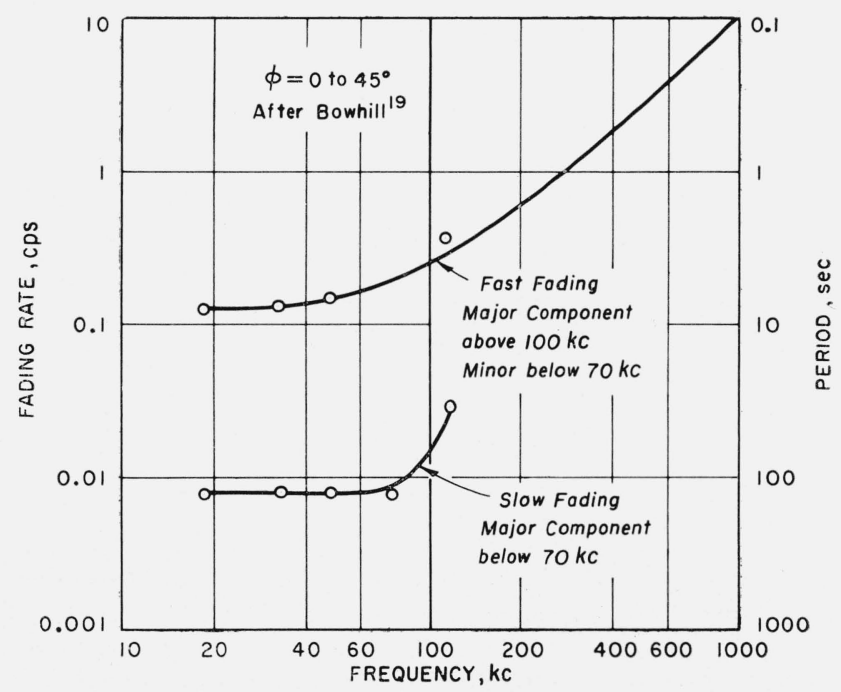

FIGURE 25. Average fading rate.

Nighttime observations at near vertical incidence. 
served by frequencies in the order of $150 \mathrm{kc}$ the average blob size appears to be $0.5 \mathrm{~km}$. Somewhat similar observations have been made by Landmark [25] although the size of the blobs he reports are somewhat larger than those expected by Bowhill.

In any event it is interesting to note the change in appearance of the ionosphere as frequency is increased in the region of $70 \mathrm{kc}$ and compare it with the nighttime ionospheric reflection coefficient presented in figure 23. Here at more nearly grazing incidence the effective change might be anticipated to occur at a lower frequency and it is possible that were sufficient data available, we would find that the reflection coefficient at night changed very little up to 30 or $50 \mathrm{kc}$ and that above this region the attenuation would increase rather rapidly.

It should be pointed out that the factor affecting the amount of convergence obtained is actually the effective roughness rather than the horizontal blob size. Norton [12] has summarized the phase sta-

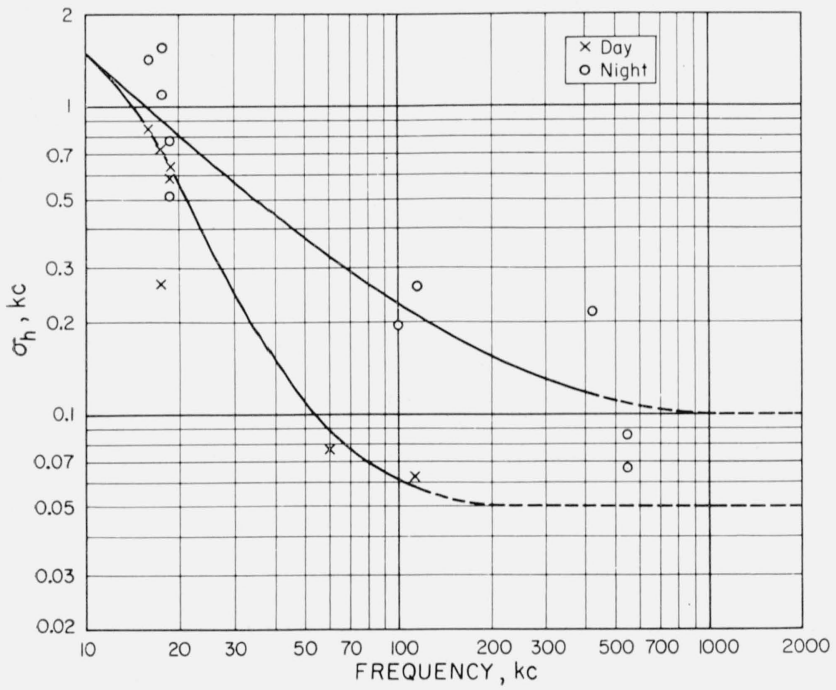

Figure 26. Median effective ionospheric roughness parameter, $\sigma_{h}$, obtained from observations of $\sigma_{\Omega}$.

$\sigma \Omega$ (degrees) $\equiv 2.4 f_{k c} \cos \phi \sigma_{h}$ (kilometers).

bility observations of a number of investigators over the frequency range of 16 to $500 \mathrm{kc}$ and the results of this study plotted in terms of ionospheric roughness is shown in figure 26 . These results indicate that the convergence shown in figure 20 is probably always valid up to $100 \mathrm{kc}$ and valid during the day up to $500 \mathrm{kc}$. At night from 200 to $500 \mathrm{kc}$ the amount of convergence present is likely to vary from zero to the full amount.

Three sample calculations for a $100 \mathrm{kc}$-frequency are included in this report and are shown in tables 1 , 2 , and 3 . The results are also shown on figures 4 and 6 . The calculations were made according to the existing conditions at the time flights 2 and 3 were made. For instance, flight 3 was made during daylight hours in northern latitudes where $\cos \chi \approx 0.2$. Our measurements indicated however, that the ionosphere was not typical of daytime conditions,
TABLE 1. Skywave field intensity calculation-Thule to Goose Path

$$
E_{s 1}=K+P_{r}-D_{p}+A_{\ell}-L_{t}-I+C_{1}-L_{r}+A_{r}+H
$$

Condition: Daytime, northern latitudes, $\cos \chi \approx 0.2, I=I$ med $+2 \mathrm{db}$

\begin{tabular}{|c|c|c|c|c|c|c|c|c|}
\hline $\begin{array}{r}\text { Distance } \\
\text { mi } \\
\psi_{1}(70 \\
\operatorname{Cos} \phi_{1}\end{array}$ & $\begin{array}{c}50 \\
57^{\circ} \\
0.83\end{array}$ & $\begin{array}{c}70 \\
47^{\circ} \\
0.75\end{array}$ & $\begin{array}{c}100 \\
37^{\circ} \\
0.60\end{array}$ & $\begin{array}{l}200 \\
20^{\circ} \\
0.38\end{array}$ & $\begin{array}{c}400 \\
9^{\circ} \\
0.22\end{array}$ & $\begin{array}{l}700 \\
3.2^{\circ} \\
0.17\end{array}$ & $\begin{array}{c}1,000 \\
0.3^{\circ} \\
0.16\end{array}$ & $\begin{array}{c}1,250 \\
-0.5^{\circ} \\
0.16\end{array}$ \\
\hline $\begin{array}{l}\bar{C}_{-} I_{-} \\
-L_{r-} \\
A_{r} \\
H\end{array}$ & $\begin{array}{r}98.2 \\
14.6 \\
-34.0 \\
-5.0 \\
0 \\
-32.7 \\
0.2 \\
6 \\
-5.0 \\
0\end{array}$ & $\begin{array}{r}98.2 \\
14.6 \\
-37.0 \\
-3.0 \\
0 \\
-32.0 \\
0.3 \\
6.0 \\
-3.0 \\
0\end{array}$ & $\begin{array}{r}98.2 \\
14.6 \\
-40.0 \\
-1.9 \\
0 \\
-30.3 \\
0.4 \\
6.0 \\
-1.9 \\
0\end{array}$ & $\begin{array}{r}98.2 \\
14.6 \\
-46.0 \\
-0.7 \\
-1.0 \\
-27.0 \\
0.6 \\
6.0 \\
-0.7 \\
0\end{array}$ & $\begin{array}{r}98.2 \\
14.6 \\
-52.0 \\
-0.2 \\
-4.0 \\
-23.4 \\
1.7 \\
6.0 \\
-0.2 \\
0\end{array}$ & $\begin{array}{r}98.2 \\
14.6 \\
-57.0 \\
-0.1 \\
-12.0 \\
-21.5 \\
5.7 \\
4.5 \\
-0.1 \\
0\end{array}$ & $\begin{array}{r}98.2 \\
14.6 \\
-60.0 \\
0 \\
-19.0 \\
-21.0 \\
6.2 \\
2.6 \\
0 \\
0\end{array}$ & $\begin{array}{r}98.2 \\
14.6 \\
-62.0 \\
0 \\
-22.0 \\
-21.0\end{array}$ \\
\hline & 42.3 & 44. 1 & 45.1 & 44 & 40.7 & 33. 3 & 21.6 & 17. \\
\hline
\end{tabular}

TABLe 2. Skywave field intensity calculation-Thule to Goose Path

$$
E_{s 1}=K+P_{r}-D_{p}+A_{t}-L_{t}-I+C_{1}-L_{r}+A_{r}
$$

Condition: $\operatorname{Cos} \chi \approx 0.2$, ionosphere low $(70 \mathrm{~km})$ with ionization

\begin{tabular}{|c|c|c|c|c|c|c|c|c|}
\hline $\begin{array}{c}\text { Distance } \\
\text { nautical } \\
\text { miles } \\
\psi_{1}(70 \mathrm{~km}) \\
\text { Cos } \phi_{1}(70 \mathrm{~km})\end{array}$ & $\begin{array}{c}70 \\
47^{\circ} \\
0.75\end{array}$ & $\begin{array}{c}100 \\
37^{\circ} \\
0.60\end{array}$ & $\begin{array}{c}200 \\
20^{\circ} \\
0.38\end{array}$ & $\begin{array}{c}400 \\
9^{\circ} \\
0.22\end{array}$ & $\begin{array}{l}700 \\
3.2^{\circ} \\
0.17\end{array}$ & $\begin{array}{c}1,000 \\
0.3^{\circ} \\
0.16\end{array}$ & $\begin{array}{c}1,250 \\
-0.5^{\circ} \\
0.16\end{array}$ & $\begin{array}{c}1,400 \\
-2^{\circ} \\
0.15\end{array}$ \\
\hline 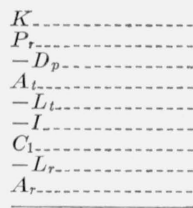 & $\begin{array}{r}98.2 \\
14.6 \\
-37.0 \\
-3.0 \\
0 \\
-11.8 \\
0.3 \\
6.0 \\
-3.0 \\
\end{array}$ & $\begin{array}{r}98.2 \\
14.6 \\
-40.0 \\
-1.9 \\
0 \\
-9.8 \\
0.4 \\
6.0 \\
-1.9 \\
\end{array}$ & $\begin{array}{r}98.2 \\
14.6 \\
-46.0 \\
-0.7 \\
-1.0 \\
-7.6 \\
0.6 \\
6.0 \\
-0.7\end{array}$ & $\begin{array}{r}98.2 \\
14.6 \\
-52.0 \\
-0.2 \\
-4.0 \\
-5.0 \\
1.7 \\
6.0 \\
-0.2\end{array}$ & $\begin{array}{r}98.2 \\
14.6 \\
-57.0 \\
-0.1 \\
-12.0 \\
-3.8 \\
5.7 \\
4.5 \\
-0.1\end{array}$ & $\begin{array}{r}98.2 \\
14.6 \\
-60.0 \\
0 \\
-19.0 \\
-3.6 \\
6.2 \\
2.6 \\
0\end{array}$ & $\begin{array}{r}98.2 \\
14.6 \\
-62.0 \\
0 \\
-20.0 \\
-3.6 \\
7.2 \\
2.0 \\
0\end{array}$ & $\begin{array}{r}98.2 \\
14.6 \\
-63.0 \\
0 \\
\mathrm{a}-20.0 \\
-3.6 \\
8.6 \\
\mathrm{~b}-12.0 \\
0\end{array}$ \\
\hline & 64.3 & 65.6 & 63.4 & 59.1 & 51.0 & 39.0 & 36.4 & 22 \\
\hline
\end{tabular}
attenuation typical of nighttime conditions.

a This low value for $L_{t}$ is due to $\psi$ being negative and the close proximity of the sea in the launching path.

b The change in $L_{r}$ is due to the crossing of the sea coast at 1,250. Thus at 1,400 the receiving antenna launching area was over arctic soil.

TABLE 3. Skywave field intensity calculation-Thule to Goose Path

$E_{s 2}=K+P_{r}-D_{p}+A_{t}-L_{t}-I_{1}+C_{2}-I_{2}-G-L_{r}+A_{r}$

Condition $\operatorname{Cos} \chi \approx 0.2$, ionosphere low $(70 \mathrm{~km})$ with ionization

\begin{tabular}{|c|c|c|c|c|c|c|}
\hline $\begin{array}{c}\text { Distance } \\
\text { nautical } \\
\text { miles } \\
\psi_{2}(70 \mathrm{~km}) \\
\operatorname{Cos} \phi_{2}(70 \mathrm{~km})\end{array}$ & $\begin{array}{c}2000^{\mathrm{a}} \\
36^{\circ} \\
0.6\end{array}$ & $\begin{array}{c}400 \mathrm{o} \\
20^{\circ} \\
0.37\end{array}$ & $\begin{array}{c}7000^{\mathrm{a}} \\
11^{\circ} \\
0.24\end{array}$ & $\begin{array}{c}1,000 \\
6^{\circ} \\
0.18\end{array}$ & $\begin{array}{c}1,250 \\
4^{\circ} \\
0.17\end{array}$ & $\begin{array}{c}1,400 \\
3^{\circ} \\
0.17\end{array}$ \\
\hline $\begin{array}{l}K \\
P_{r-} \\
-D_{p-} \\
A_{t-\ldots} \\
-L_{t-} \\
-I_{1-} \\
C_{2}\end{array}$ & $\begin{array}{r}98.2 \\
14.6 \\
-48.0 \\
-1.9 \\
0 \\
-10.0 \\
0.2 \\
-10.0 \\
0 \\
6.0 \\
-1.9\end{array}$ & $\begin{array}{r}98.2 \\
14.6 \\
-53.0 \\
-0.7 \\
-1.0 \\
-7.5 \\
0.4 \\
-7.5 \\
0 \\
6.0 \\
-0.7\end{array}$ & $\begin{array}{r}98.2 \\
14.6 \\
-57.0 \\
-0.2 \\
-4.0 \\
-5.0 \\
1.5 \\
-5.0 \\
0 \\
6.0 \\
-0.2\end{array}$ & $\begin{array}{r}98.2 \\
14.6 \\
-60.0 \\
-0.1 \\
-7.0 \\
-4.0 \\
2.0 \\
-4.0 \\
0 \\
5.5 \\
-0.1\end{array}$ & $\begin{array}{r}98.2 \\
14.6 \\
-62.0 \\
-0.1 \\
-10.0 \\
-4.0 \\
3.5 \\
-4.0 \\
\mathrm{~b}-3.0 \\
5.0 \\
-0.1\end{array}$ & $\begin{array}{r}98.2 \\
14.6 \\
-63.0 \\
0 \\
-12.0 \\
-4.0 \\
5.0 \\
-6.0 \\
\mathrm{~b}-3.0 \\
\mathrm{c}-2.5 \\
0\end{array}$ \\
\hline$E_{s 2 \ldots}$ & 47.2 & 48.8 & 48.9 & 45.1 & 38.1 & 27 \\
\hline
\end{tabular}
attenuation typical of nighttime conditions.

a Whenever the sky ray distance $\left(D_{s}\right)$ is appreciably different from the surface distance $(D)$, see figure 16 to calculate $D_{s}$ and use this value to calculate $D_{p}$.

b At these distances the ground reflection point was on Baffin Island.

c At this point the receiving antenna was over land instead of sea as it had been up to 1,250 nautical miles. 
and we chose a typical daytime ionospheric height of $70 \mathrm{~km}$ with ionospheric reflection values for normal nighttime conditions. Conditions for flight 2 were considered to be normal for summer daytime conditions in northern latitudes. Since $\cos \chi \approx 0.2$ at these latitudes during the summer, we used ionospheric reflection values close to what we have indicated on figure 22 as typical values for winter noon conditions

The authors acknowledge the assistance received from K. A. Norton, J. R. Wait, and J. S. Belrose during many helpful discussions of these problems as well as for the permission to use material prepared by them. In addition, they are indebted to: Col. W. E. Geyser of AACS for his interest and assistance in making this work possible, and the personnel under his command including O. E. Cummings who made the aircraft measurements of flight $2 ; \mathrm{R}$. M. Coon and E. F. Florman for helpful discussions and assistance in obtaining the data; Winifred Mau for her assistance during the preparation of this manuscript; J. C. Harman for preparation of the illustrations; and to W. W. Brown for permission to use some of his vlf observations. The cooperation of J. E. Gillis, A. B. Nicolaou, and Hans Roethlisberger of the Snow, Ice, and Permafrost Research Establishment, and Comdr. C. Santae, USN, is also appreciated.

\section{References}

[1] J. R. Wait, Transmission curves for ground-wave propagation at low radio frequencies, Radio Physics Lab., Defence Research Telecommunications Establishment, Ottawa, Canada, rept. No. R-1, April, 1953.

[2] G. Millington, Ground-wave propagation over an inhomogeneous smooth earth, Proc. Inst. Elec. Engrs. London 96 Pt. III, 53 (1949).

[3] J. R. Wait, Mixed-path ground-wave propagation, I and II, J. Research NBS 5\%, 1 (1956) RP 2687; and 59, 19 (1957) RP 2770.

[4] J. R. Wait, The amplitude and phase of the low-frequency ground wave near a coastline, J. Research NBS 58, 237 (1957) RP2756.

[5] J. R. Wait and A. Murphy, The influence of a ridge on the low-frequency ground wave, J. Research NBS $\mathbf{5 8}$, 1 (1957) RP2727.

[6] F. E. Terman, Radio Engineers Handbook, sec. 11 (McGraw-Hill Book Co., New York, N.Y., 1943).

[7] J. R. Wait and W. A. Pope, Input resistance of L.F. unipole aerials, Wireless Eng. 32, 131 (1955).
[8] K. A. Norton, The calculation of ground-wave field intensities over a finitely conducting spherical earth, Proc. I.R.E. 29, 623 (1941).

[9] N. E. Dorsey, Properties of ordinary water substance (Reinhold Publishing Corp., New York, N.Y., 1940).

[10] J. R. Wait and A. Conda, Trans. I.R.E., AP-6 (October 1958).

[11] K. A. Norton and A. C. Ombert, The maximum range of a radar set, Proc. I.R.E. 35, 4 (1947).

[12] K. A. Norton, (Informal communication, July 1958).

[13] R. N. Bracewell, K. G. Budden, J. A. Ratcliffe, T. W. Straker, and K. Weekes, The ionospheric propagation of low- and very-low-frequency radio waves over distances less than $1000 \mathrm{~km}$, Proc. Inst. Elec. Engrs. London 98 Pt. III, 221 (1951).

[14] A. H. Waynick, The present state of knowledge concerning the lower ionosphere, Proc. I.R.E. 45, 741 (1957).

[15] J. E. Bickel, J. L. Heritage, and S. Weisbrod, An experimental measurement of vlf field strength as a function of distance, using an aircraft, U.S. Navy Electronics Lab., San Diego, Calif., rept. No. 767, Jan. 28, 1957.

[16] J. S. Belrose, Some investigations of the lowest ionosphere (Doctoral Thesis, University of Cambridge, 1958).

[17] J. E. Bickel, A method for obtaining lf oblique-incidence reflection coefficients and its application to 135.6 $\mathrm{kc} / \mathrm{s}$ data in the Alaskan area, J. Geophys. Research 62, 373 (1957).

[18] Rune Lindquist, Preliminary results of an investigation of propagation conditions at very low frequencies, Union Radio Scientifique Internationale, Boulder, XII General Assembly Document, 1957/No. 104/Commission III.

[19] Weekes and Stuart, The ionospheric propagation of radio waves with frequencies near $100 \mathrm{kc} / \mathrm{s}$ over distances up to $1000 \mathrm{~km}$, Proc. Inst. Elec. Engrs. London $99 \mathrm{Pt}$. IV, 38 (1952)

[20] S. A. Bowhill, The fading of radio waves of frequencies between 16 and $2400 \mathrm{kc} / \mathrm{s}$, J. Atmospheric and Terrest. Phys. 8, 129 (1956).

[21] J. R. Wait and L. B. Perry, Calculations of ionospheric reflection coefficients at very-low radio frequencies, J. Geophys. Research 62, 43 (1957).

[22] J. R. Wait, The mode theory of vlf ionospheric propagation for finite ground conductivity, Proc. I.R.E. 45, 760 (1957).

[23] J. R. Pierce, Sky-wave field intensity I. Low- and verylow radio frequencies, Cruft Lab. tech. rept. 158 (Harvard U., Cambridge, Mass., Sept. 1, 1952).

[24] A. D. Watt, R. M. Coon, E. L. Maxwell, and R. W. Plush (informal communication, 1957).

[25] B. Landmark, The fading of radio waves reflected from the E layer, J. Atmospheric and Terrest. Phys. 10, 288 (1957).

Boulder, Colo. (Paper 63D1-12). 